\title{
Small opacities among dental laboratory technicians in Copenhagen
}

\author{
D SHERSON, N MALTBÆK, O OLSEN \\ From Medical Department $P$ and the Chest Clinic, Bispebjerg Hospital, Copenhagen, Denmark
}

ABSTRACT After a case of advanced pneumoconiosis occurred in a dental laboratory technician, 31 other dental technicians and 30 control subjects controlled for smoking habits, sex, and age were investigated. More technicians (55\%) than controls $(30 \%)$ had at least grade 1 dyspnoea $(\mathrm{p}>0.05)$. Multiple regression analysis showed that 13 technicians who had produced dental prostheses for at least 15 years had consistently lower lung function $\left(\mathrm{FVC}, \mathrm{FEV}_{1}, \mathrm{FEV}_{1} / \mathrm{FVC}, \mathrm{MEF}_{50}\right.$, and DCO single breath), although the differences were not statistically significant. All mean lung function values for technicians and controls were within normal limits. Increases in $\mathrm{MEF}_{50}$ after breathing $80 \%$ helium and $20 \% \mathrm{O}_{2}$ failed to show small airways dysfunction among the technicians. Of the six with radiological pneumoconiosis ( 5 simple, 1 advanced) four had symptoms. All three biopsy specimens showed varying degrees of pulmonary fibrosis. DCO single breath was diminished in four of the six. One male dental technician had scleroderma and possibly Erasmus syndrome. Blind readings showed an increased number of suspicious chest $x$ rays films ( $\geqslant$ category $0 / 1$ ) among older smokers and exsmokers $(\mathrm{p}=0.013)$ regardless of occupation. Our results support other evidence that dental technicians are at risk of developing pneumoconiosis. Therefore, adequate hygienic control of dental laboratories is indicated.

Dental laboratory technicians may be exposed to several potentially toxic materials. Non-precious metal alloys containing chromium, cobalt, molybdenum, beryllium, or nickel are used in the production of crowns, bridges, and dentures. ${ }^{12}$ Liners with asbestos may be used in casting procedures and methylmethacrylate in the preparation of dentures. ${ }^{3}$ Silica is used as a sandblasting abrasive and is also present in porcelain. A powder containing $75 \%$ silica is sometimes used as refractory investment material for casting procedures. ${ }^{4}$ Polishing materials may contain iron, aluminium, silica, and chromium. Pneumoconioses have been described in dental technicians caused by various presumed agents: beryllium, ${ }^{25}$ silica ${ }^{46}$ and metals (cobalt, chromium, tungsten, molybdenum) with or without silica. ${ }^{7-11}$ Analysis of lung biopsy specimens has shown the presence of various metals and silica. ${ }^{57811}$

Several epidemiological studies have been carried out to investigate the prevalence of pneumoconiosis and lung function abnormalities among dental technicians. Lob and Hugonnaud described suspicious chest $x$ ray changes suggestive of hard metal pneumoconiosis in five out of 24 subjects. $^{7}$ Of the 70

Accepted 11 May 1987 dental technicians studied by Kronenberger et al, 53 had chest $x$ ray films showing reticulonodular interstitial markings: 26 delicate (category 0), 25 distinct (category 1), and two pronounced (category 2). ${ }^{9}$ The $x$ ray films were read according to ILO $\mathrm{u} / \mathrm{c}$ classification of pneumoconiosis, 1971. When lung function among this group of 70 was compared with 70 control subjects there was no significant difference with regard to inspiratory vital capacity, $\mathrm{FEV}_{1}$, or DCO single breath. Only $\mathrm{PaO}_{2}$ was significantly lower among dental technicians. ${ }^{12}$ Eight of 178 dental technicians studied by Rom et al had simple pneumoconiosis (category $1 / 0$ or $1 / 1) .{ }^{2}$ The only significant difference in lung function, compared with a control group of 69 , was an association between exposure-years and reduced FVC and FEV, for non-smoking male technicians.

A 37 year old dental technician with advanced silicosis was studied at Bispebjerg Hospital, Copenhagen. ${ }^{4}$ After this index case, an epidemiological study of dental technicians in the greater Copenhagen area was performed. We were interested in defining the prevalence of pneumoconiosis as well as investigating the presence of small airways disease (subtle dysfunction of airway obstruction) using flow volume curves after helium- $\mathrm{O}_{2}\left(\mathrm{HeO}_{2}\right)$ breathing. An attempt was 
also made to determine which job process was particularly hazardous.

\section{Materials and methods}

\section{STUDY SUBJECTS}

Subjects $(\mathrm{n}=31)$ were selected from membership lists of the Danish Dental Technicians Union using the following criteria: (1) living in the greater Copenhagen area, (2) minimum of five years employment as a dental laboratory technician with exposure to silica, and (3) no previous employment in a dusty job other than as a dental technician. The mean duration of employment was $20 \cdot 1$ years (range: $6-41$ ). Five had been employed for six to nine years, 12: 10-19 years, seven: 20-29 years, and seven: 30 years or more. Control subjects $(n=30)$ were administrative or office workers from Bispebjerg Hospital who had never been employed in a dusty job. The group was controlled for smoking habits, sex, and age. The five ex-smokers were reclassified: three as non-smokers ( $<4$ pack-years) and two as smokers ( $>9$ pack-years). Cigars $(5 \mathrm{~g}$ tobacco/cigar) and cheroots ( $3 \mathrm{~g}$ tobacco/cheroot) were translated to cigarettes ( $1 \mathrm{~g}$ tobacco/cigarette) (table 1).

MEDICAL QUESTIONNAIRE AND TESTS

A self administered questionnaire containing stan-

Table 1 Comparison of dental technicians and control subjects

\begin{tabular}{lcc}
\hline & $\begin{array}{c}\text { Control } \\
\text { subjects }\end{array}$ & $\begin{array}{l}\text { Dental } \\
\text { technicians }\end{array}$ \\
\hline Men & 18 & 18 \\
Women & 12 & 13 \\
Smokers & 23 & 23 \\
Non-smokers & 7 & 8 \\
Mean pack-years & $24 \cdot 0$ & $23 \cdot 3$ \\
for smokers & $43 \cdot 2$ & $42 \cdot 1$ \\
Mean age (years) & $172 \cdot 6$ & $172 \cdot 9$ \\
Mean height (cm) & $71 \cdot 0$ & $70 \cdot 1$ \\
Mean weight (kg) & & \\
\hline
\end{tabular}

dardised work histories, the WHO standardised dyspnoea questions, ${ }^{13}$ and the British Medical Research Council's standardised chronic bronchitis questions ${ }^{14}$ was sent to all participants and subsequently checked in a personal interview. All participants had full sized chest $x$ ray films classified according to the 1980 International Classification of Radiographs of Pneumoconioses ${ }^{15}$ by four readers $(2$ chest physicians, 1 radiologist, 1 specialist in occupational diseases) in a blind fashion.

Hewlett-Packard's pulmonary calculator system 47804A with pneumotach was used to measure flow volume curves and DCO-single breath (SB) controller 47305A to measure diffusing capacity (transfer factor). Daily calibration was performed using separately atmospheric air and a mixture of $80 \%$ helium and $20 \% \mathrm{O}_{2}$. The best of a minimum of three flow volume curves was chosen. To test density dependence, flow volume curves were measured immediately after three vital capacity inspirations of $80 \%$ helium and $20 \% \mathrm{O}_{2}$ $\left(\mathrm{HeO}_{2}\right)$. FVC breathing air and FVC breathing $\mathrm{HeO}_{2}$ had to agree within $5 \% .^{16}$ DCO-SB was performed before $\mathrm{HeO}_{2}$ breathing because $\mathrm{He}$ was also used in DCO-SB calculations. Maximum expiratory flow volume (MEF) curves with air and $\mathrm{HeO}_{2}$ were used to measure flow at $50 \%$ FVC $\left(\mathrm{MEF}_{50}\right.$ air and $\mathrm{MEF}_{50}$ $\left.\mathrm{HeO}_{2}\right)$. The percentage difference $\left(\triangle \mathrm{MEF}_{50}\right)$ was calculated as follows:

$$
\Delta \mathrm{MEF}_{50}=\frac{\mathrm{MEF}_{50} \mathrm{HeO}_{2}-\mathrm{MEF}_{50} \text { air }}{\mathrm{MEF}_{50} \text { air }} \times 100
$$

Volume of iso flow could not be measured as data were derived on line by computer analysis. Predicted values (tables 2 and 3) were obtained from Knudson et al $^{17}$ (spirometry) and Kanner and Morris ${ }^{18}$ (DCO-SB). Statistical methods included the one tailed $t$ test, multiple linear regression, and the chi-squared test.

\section{Results}

SYMPTOMS AND LUNG FUNCTION

There were no significant differences between dental

Table 2 Description of six dental technicians with simple pneumoconiosis

\begin{tabular}{|c|c|c|c|c|c|c|c|c|}
\hline \multirow[b]{2}{*}{ No } & \multirow[b]{2}{*}{ Age } & \multirow{2}{*}{$\begin{array}{l}\text { Total years } \\
\text { employed (years } \\
\text { producing } \\
\text { chromium-cobalt } \\
\text { prostheses) }\end{array}$} & \multirow[b]{2}{*}{$\operatorname{Sex}$} & \multirow[b]{2}{*}{$\begin{array}{l}\text { Smoking } \\
\text { pack-years }\end{array}$} & \multicolumn{4}{|c|}{ Pulmonary function values ( $\%$ prediicted) } \\
\hline & & & & & $F V C$ & $F E V$, & $F E V, / F V C$ & $\begin{array}{l}D C O-S B(\mathrm{ml} / \\
\mathrm{min} / \mathrm{mm} \mathrm{Hg})\end{array}$ \\
\hline $\begin{array}{l}1 \\
2 \\
3 \\
4 \\
5 \\
6\end{array}$ & $\begin{array}{l}60 \\
39 \\
48 \\
41 \\
61 \\
46\end{array}$ & $\begin{array}{l}38(5) \\
14(10) \\
23(23) \\
17(17) \\
41(35) \\
29(29)\end{array}$ & $\begin{array}{l}\mathrm{M} \\
\mathrm{M} \\
\mathrm{M} \\
\mathrm{M} \\
\mathrm{F} \\
\mathrm{M}\end{array}$ & $\begin{array}{r}53 \\
32 \\
50 \\
8 \\
45 \\
45\end{array}$ & $\begin{array}{l}3 \cdot 29(73) \\
5 \cdot 39(115) \\
3 \cdot 71(71) \\
3 \cdot 40(83) \\
3 \cdot 50(112) \\
3 \cdot 75(80)\end{array}$ & $\begin{array}{l}2.05(58) \\
2.75(75) \\
2.75(66) \\
1.98(61) \\
2.00(80) \\
2.53(67)\end{array}$ & $\begin{array}{l}0.62(78) \\
0.52(63) \\
0.74(92) \\
0.58(70) \\
0.57(70) \\
0.68(83)\end{array}$ & $\begin{array}{l}17 \cdot 35(69) \\
22 \cdot 58(84) \\
11 \cdot 34(37) \\
15 \cdot 43(65) \\
12 \cdot 37(61) \\
22 \cdot 79(83)\end{array}$ \\
\hline Mean $(\bar{x})$ & 49 & $27(20)$ & & 39 & & & & \\
\hline
\end{tabular}


Table 3 Multiple regression analysis of estimated difference in lung function between control subjects and dental technicians (DT) with $<15$ years or $\geqslant 15$ years employment with production of prostheses (all types). The mean lung function of $D T s$ with $\geqslant 15$ years employment is arbitrarily set at 0

\begin{tabular}{|c|c|c|c|}
\hline \multirow[b]{2}{*}{ Parameter } & \multicolumn{3}{|c|}{ Mean estimate of lung function } \\
\hline & $\begin{array}{l}\text { Control group } \\
(n=30)\end{array}$ & $\begin{array}{l}\text { DTs with }<15 \\
\text { yrs }(n=18)\end{array}$ & $\begin{array}{l}D T s \geqslant 15 \text { yrs } \\
(n=13)\end{array}$ \\
\hline 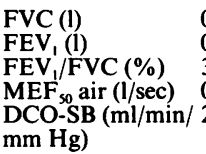 & $\begin{array}{l}0 \cdot 11 \\
0 \cdot 21 \\
3 \cdot 73 \\
0 \cdot 47 \\
2 \cdot 61\end{array}$ & $\begin{array}{l}0.25 \\
0 \cdot 15 \\
0.76 \\
0.48 \\
3.60\end{array}$ & $\begin{array}{l}0 \\
0 \\
0 \\
0 \\
0\end{array}$ \\
\hline
\end{tabular}

All $p$ values $>0.05$.

technicians or control subjects in respect of the prevalence of chronic bronchitis or dyspnoea. Eight of the $30(27 \%)$ dental technicians and six of the $28(21 \%)$ controls had chronic bronchitis whereas 16 of the 29 (55\%) dental technicians and eight of the $27(30 \%)$ controls had grade 1 dyspnoea $(p>0.05)$.

The results of the lung function studies are presented in table 3. Multiple regression analyses were controlled for age, height, sex, and smoking habits. The 13 dental technicians who had been employed at least 15 years producing all types of prostheses (gold or chromium cobalt) had consistently lower lung function. Nevertheless, no significant differences were found. The mean improvement in flow after $\mathrm{HeO}_{2}$ breathing $\left(\triangle M E F_{50}\right)$ was $13 \%(1 \mathrm{SD}=14.75)$ for all dental technicians and $14 \%(1 \mathrm{SD}=15.95)$ for all controls. All mean lung function values were within normal limits.

\section{$X$ RAY FINDINGS}

Four of the 31 dental technicians and one of the 30 control subjects had small opacities $(\geqslant$ category $1 / 0)$ with agreement among three of the four readers ( $p>$ 0.05 ). The chest $x$ ray films were read independently in a blind fashion. It was accepted that one of the three positive readings for one dental technician was $0 / 1$.

Table 4 Smoking habits and suspicion of small opacities $(\geqslant 0 / 1)$ among 31 dental technicians and 30 control subjects without regard to occupation

\begin{tabular}{llll}
\hline & Normal & $\begin{array}{l}\text { Suspicion of } \\
\text { small opacities }\end{array}$ & Total \\
\hline Smokers and & & & \\
$\quad$ ex-smokers & 27 & 22 & 49 \\
Non-smokers & 11 & 1 & 12 \\
Total & 38 & 23 & 61 \\
\hline
\end{tabular}

$\mathrm{p}=0.0219$.
Table 5 Age and suspicion of small opacities ( $\geqslant 0 / 1)$ among 49 smokers and ex-smokers, dental technicians, and control subjects without regard to occupation

\begin{tabular}{llll}
\hline Age & Normal & $\begin{array}{l}\text { Suspicion of } \\
\text { small opacities }\end{array}$ & Total \\
\hline $16-39$ & 19 & 6 & 23 \\
$40-62$ & 10 & 16 & 26 \\
& 27 & 22 & 49 \\
\hline
\end{tabular}

$p=0.013$.

There was a significantly increased number of smokers and ex-smokers with suspicious chest $x$ ray films compared with non-smokers (table 4). An $x$ ray film was classified as suspicious if one or more of the readers classified it as $\geqslant 0 / 1$ (blind readings). In a similar manner one could demonstrate a significantly increased number of suspicious $x$ ray films among older smokers and ex-smokers without regard to occupation (table 5).

Of the four dental technicians with small opacities (agreement among 3/4 readers) two were symptomatic: subjects 1 and 6 in table 2 . Subject 4 had an advanced pneumoconiosis $(3 / 3 \mathrm{r}$ B) for which he received compensation. Subject 5 had a positive ANA, abnormal bronchoalveolar lavage $(23 \%$ lymphocytes), increased lung gallium-67 index: right = 0.51 and left $=0.53$ (normal 0.28 ), ${ }^{19}$ and a transbronchial lung biopsy showing non-specific lung fibrosis with some birefringent particles observed by polarised light microscopy. Two other dental technicians had radiological pulmonary fibrosis diagnosed by the radiology department (with only one or two of our readers classifying the $x$ ray films as $\geqslant 1 / 0$ ). Subject 2 had a spontaneous pneumothorax. Lung biopsy specimens taken during pleuroscopy showed PAS positive and iron positive particles within alveolar macrophages and some thickening of the alveolar walls. Subject 3 had diffuse scleroderma with advanced fibrosis, proliferation of blood vessels, and some birefringent particles shown by open lung biopsy. Table 2 gives the smoking habits, work histories, and lung function test results for the six dental technicians with radiological pulmonary fibrosis. Diffusing capacity was diminished in four of the six but none had radiological changes of emphysema.

The six dental technicians with simple pneumoconiosis $(19.4 \%)$ were mainly employed in the production of chromium cobalt prostheses (table 2). None of the 12 dental technicians who had never worked at this process had simple pneumoconiosis. Of the eight workers with less than 10 years employment producing chromium cobalt prostheses $(\overline{\mathrm{x}}=5)$, one had simple pneumoconiosis $(12.5 \%)$. Of the 11 workers 
with $\geqslant 10$ years experience producing these prostheses $(\bar{x}=19 \cdot 6)$, five had simple pneumoconiosis $(45 \cdot 5 \%)$.

\section{Discussion}

There is now sufficient evidence to conclude that dental technicians are at risk of developing pneumoconiosis. ${ }^{20}$ Apparently silica, beryllium, chromium, or cobalt may be causative agents. Our index case used Multivest powder $(50 \%$ quartz and $25 \%$ cristobalite) as a refractory investment material for casting procedures. ${ }^{4} \mathrm{He}$ used as much as $6 \mathrm{~kg}$ daily for six years without ventilation. Percutaneous lung biopsy showed iron positive material that could not be identified by light microscopy and advanced interstitial fibrosis. Unfortunately lung tissue was not studied in either our index case or the subjects in the epidemiological study by scanning electron microscopy to define its particle content.

A precise exposure history for our dental technicians was difficult to define. Most were employed at small laboratories where it was necessary to grind and polish as well as produce prostheses. Thus there was a mixed exposure to silica and methyl methacrylate in addition to various metals. Unfortunately, no air sampling was undertaken to define exposures quantitatively.

We were able carefully to match our study subjects with a control group (table 1). Almost twice as many dental technicians $(55 \%)$ had at least grade 1 dyspnoea compared with the controls $(30 \%)$. This difference, however, was not statistically significant, possibly due to insufficient numbers. Rom et al could not show excess symptoms among dental technicians. ${ }^{2}$ Study subjects with a minimum of 15 years producing prostheses had consistently lower lung function (table 3 ). There were, however, no significant differences. All mean spirometric parameters and DCO-SB for controls and the exposed group were normal as in Rom's study. ${ }^{2}$

Measurements of maximum expiratory flow (MEF) while breathing gases of varying density (air versus $\mathrm{HeO}_{2}$ ) has shown small airways dysfunction in smokers. ${ }^{21}$ Flow volume curves after $\mathrm{HeO}_{2}$ breathing have been used to investigate the effect of hair spray ${ }^{22}$ and cotton dust ${ }^{23}$ on small airways. Nevertheless, the pathological correlation with density dependence of MEF may be poor. ${ }^{24}$ The mean per cent increase in flow after $\mathrm{HeO}_{2}$ breathing $\left(\triangle \mathrm{MEF}_{50}\right)$ was almost identical in our two groups: dental technicians $(13 \%)$ and controls $(14 \%)$. Thus we could not show the presence of small airways disease using this technique. The procedure used in measuring MEF immediately after $\mathrm{HeO}_{2}$ breathing was extremely difficult. It was often difficult to obtain FVC breathing air that agreed with $5 \%$ of $\mathrm{FVC}$ breathing $\mathrm{HeO}_{2}$. We agree with
Knudson et al that $\mathrm{HeO}_{2}$ breathing with $\triangle \mathrm{MEF}_{50}$ is not a suitable screening tool under field survey conditions. ${ }^{16}$

We were not able to show a statistically significant increase in the prevalence of simple pneumoconioses $(\geqslant 1 / 0)$ in dental technicians $(4 / 31=12.9 \%)$ compared with controls $(1 / 30=3.3 \%)$ with agreement among three or four readers. A prevalence of $12.9 \%$, however, is much higher than is found in the general population $(\leqslant 3 \cdot 7 \%) .{ }^{25}$ Our dental technicians had an increased relative risk of developing small opacities: $12 \cdot 9 / 3 \cdot 3=3 \cdot 9$.

Surprisingly, the prevalence of suspicious chest $x$ ray films $(\geqslant 0 / 1)$ was significantly higher among older smokers (tables 4 and 5) without regard to occupation. This observation among smokers is in opposition to the accepted opinion that cigarette smoking does not produce radiological pulmonary fibrosis, ${ }^{26}$ although there may be synergism between asbestos and cigarette smoking. ${ }^{25}$ These data, however, should be interpreted cautiously as "suspicious chest $x$ ray films" is an uncertain evaluation despite blind readings.

Of the six dental technicians with simple pneumoconiosis (subject 4 had also advanced changes) four were symptomatic (table 2). All three lung biopsy specimens showed varying degrees of fibrosis. The pattern of fibrosis and its specific aetiology could not be determined. The production of chromium cobalt prostheses, however, appears to be the most hazardous job process. The Erasmus syndrome (association of scleroderma and pneumoconiosis) has been described in a dental technician ${ }^{10}$ and it is possible that subject 3 had this syndrome. It is important that all products used in dental laboratories are properly labelled and that dental technicians are well informed about the potential hazards. The experience now gathered concerning pneumoconiosis among dental technicians indicates the need for effective ventilation of these laboratories and the substitution of dangerous materials when possible.

We express our gratitude to the Danish Dental Technicians Union for their help as well as to the Danish National Association against Tuberculosis and other Pulmonary Diseases for their generous financial support. We are also grateful to $\mathrm{Dr} \mathrm{Kaj}$ Viskum, Dr Thomas Heckscher, Dr Gregers Thomsen, and Dr Philippe Grandjean for help with classifying the chest $x$ ray films. We are very appreciative of the help provided by Dr Ib Hansen and Mrs Ulla Lund, Department of Occupational Medicine, Vejle Hospital, in preparing this article.

\section{References}

I Brune D, Beltesbrekke H, Melson S. Dust in workroom air of 
dental laboratories. Swed Dent J 1981;5:247-51.

2 Rom WN, Lockey JE, Lee JS, et al. Pneumoconiosis and exposures of dental laboratory technicians. Am J Public Health 1984;74:1252-7.

3 Brune D, Beltesbrekke $\mathrm{H}$. Levels of methylmethacrylate, formaldehyde and asbestos in dental workroom air. Scand J Dent Res 1981;89:113-6.

4 Hansen HM. A dental technician with silicosis. Ugeskr Laeger 1983;145:2378-9.

5 Hugonnaud C, Lob M. Preliminary survey on occupational hazards by dental technicians working on metallic prostheses. Médecine Sociale et Préventive 1976;21:139.

6 Briotet A, Magrex LL, Parant C, et al. The risk of silicosis among dental technicians. Archives des Maladies Professionelles de Medicine du Travail et de Securité Sociale 1979;40:122-3.

7 Lob M, Hugonnaud C. Risks of pneumoconiosis due to hard metals and berylliosis in dental technicians during the modelling of metal prostheses: pulmonary pathology. Archives des Maladies Professionelles de Medicine du Travail et de Securité Sociale 1977;38:543-9.

8 Carles P, Fabre J, Pujol M, Duprez A, Bollinelli R. Complex pneumoconiosis in dental prosthesis makers. Le Poumon et le Coeur 1978;34:189-92.

9 Kronenberger $\mathrm{H}$, Morgenroth $\mathrm{K}$, Tuengerthal S, et al. Pneumoconiosis of a dental technicians' collective. Atemwegsund Lungenkrankheiten 1980;6:279-82.

10 Leclerc P, Fiessinger J-N, Capron F, Ameille J, Rochenmaure J. The Erasmus syndrome in a dental technician: value of prevention of occupational diseases. Ann Med Interne 1983;134:653-5.

11 De Vuyst $P$, Vande Weyer R, De Coster A, et al. Dental technician's pneumoconioses: a report of two cases. Am Rev Respir Dis 1986;133:316-20.

12 Kronenberger H, Kappos AD, Müller J, Meier-Sydow J. Lung function in dental technicians in comparison to occupationally non-exposed controls. Am Rev Respir Dis 1984;129:179.

13 Rose GA, Blackburn H. Cardiovascular survey methods. Geneva: World Health Organisation, 1968:176 (Monograph series No 56.)

14 Medical Research Council. Committee on aetiology of chronic bronchitis. Lancet 1965;i:775-9.
15 International Labour Office. Guidelines for the use of ILO international classification of radiographs of pneumoconiosis. Rev ed. Geneva: International Labour Office, 1980. (Occupational Safety and Health series, No 22.)

16 Knudson RJ, Bloom JW, Kaltenborn WT, Burrows B, Lebowitz MD. Assessment of air vs helium-oxygen flow-volume curves as an epidemiologic screening test. Chest 1984;86:419-23.

17 Knudson RJ, Slatin RC, Lebowitz MD, Burrows B. The maximal expiratory flow-volume curve: normal standards, variability and effects of age. Am Rev Respir Dis 1976;113:587-600.

18 Kanner RE, Morris AH, eds. Clinical pulmonary function testing. Salt Lake City: Intermountain Thoracic Society, 1975.

19 Wesselius LJ, Witztum KF, Taylor AT, Hartman MT, Moser KM. Computer assisted versus visual lung gallium-67 index in normal subjects and in patients with interstitial lung disorders. Am Rev Respir Dis 1983;128:1084-9.

20 Anonymous. Lung disease in dental laboratory technicians (Editorial). Lancet 1985; i:1200-1.

21 Dosman J, Bode F, Urbanetti J, Martin R, Macklem PT. The use of a helium-oxygen mixture during maximum expiratory flow to demonstrate obstruction in small airways in smokers. J Clin Invest 1975;55:1090-9.

22 Zuskin E, Loke J, Bouhuys A. Helium-oxygen flow-volume curves in detracting acute response to hair spray. Int Arch Occup Environ Health 1981;49:41-4.

23 Bradford JM, Duffell GM, Ingram RH. Testing for small airways obstruction in occupational exposed workers: a pilot project in cotton workers. In: Dosman JA, Cotton DJ, eds. Occupational pulmonary disease: focus on grain dust and health. New York: Academic Press, 1980:127-39.

24 Paré PD, Brooks LA, Coppin CA, et al. Density-dependence of maximal expiratory flow and its correlation with small airway disease in smokers. Am Rev Respir Dis 1985;131:521-6.

25 Kilburn KH, Lilis R, Anderson HA, Miller A, Warshaw RH. Interaction of asbestos, age and cigarette smoking in producing radiographic evidence of diffuse pulmonary fibrosis. $\mathrm{Am} \mathrm{J} \mathrm{Med}$ 1986;80:377-81.

26 Kilburn KH. Cigarette smoking does not produce or enhance the radiologic appearance of pulmonary fibrosis. Am J Ind Med 1981;2:305-8. 